\title{
Behaviour of short and long cracks in air and in liquid metal in T91 steel
}

\author{
Jean-Bernard Vogt $^{1, *}$, Carla Carle, Jérémie Bouquerel ${ }^{1}$, and Ingrid Proriol Serre ${ }^{1}$ \\ ${ }^{1}$ Univ. Lille, CNRS, INRA, ENSCL, UMR 8207 - UMET - Unité Matériaux et Transformations, F-59000 Lille, France
}

\begin{abstract}
The low cycle fatigue behaviour of a $9 \mathrm{Cr} 1 \mathrm{MoNbV}$ martensitic steel has been investigated at $350^{\circ} \mathrm{C}$ in air and in lead-bismuth eutectic (LBE). Total strain controlled tests were performed from $\Delta \varepsilon_{\mathrm{t}}=$ $0.40 \%$ to $1.2 \%$. The material exhibited a pronounced cyclic softening in both environments. LBE reduced the fatigue resistance. LBE accelerated the formation of the long crack by promoting the growth of the first short cracks. A clear change in propagation mode was observed. In air, ductile fatigue striations were observed while in LBE a brittle fracture decorated by voluminous and largely spaced striations were visible. From EBSD analysis, it was concluded that in LBE, the long crack advanced quickly by repeated and discontinuous cleavage.
\end{abstract}

\section{Introduction}

T91 martensitic steel is a modified grade of the $9 \mathrm{Cr} 1 \mathrm{Mo}$ steel family. It exhibits excellent combination of strength and ductility which can be achieved by control of the heat treatment. With the addition of $\mathrm{Nb}$ and $\mathrm{V}$, T91 is particularly chosen for application where creep resistance is required. It is therefore employed for structural components in all industrial fields working at high temperatures such as refineries or power plants. With an amount of chromium less than $10.5 \mathrm{wt} \%$, the alloy cannot be classified as stainless steel and is not really designed to operate in corrosive environments as can do the $12 \mathrm{Cr}$ steels.

T91 steel has been considered as one of the materials to be possibly employed for components of accelerator driven systems (ADS) or of Gen IV nuclear reactors. These systems employ liquid metals as spallation target or as coolant. Even if the ductility of T91 is somewhat appreciable, it can be decreased by irradiation e.g. [1] or by long term exposure at high temperature e.g. [2]. Besides these operating conditions that affect the bulk of the material, damage initiation by the liquid metal environment may occur as it is the case for aqueous environments e.g. [3]. Liquid metals do not involve similar corrosion mechanism as aqueous environments. Electrochemical corrosion is not a process that occurs when metallic alloys are in contact with a liquid metal.

A very amazing response that can exhibit a ductile material stressed in liquid metal is the so called liquid metal embrittlement (LME) or liquid metal assisted damage (LMAD). It has been shown by several authors working in the field of materials in contact with lead bismuth eutectic (LBE) that T91 is especially sensitive. For T91, the ductile to brittle transition in $\mathrm{LBE}$ at $300^{\circ} \mathrm{C}$ is strongly influenced by the heat treatment and especially the tempering temperature [4].

The objective of the paper is to study the effect of LBE on the mechanical response and on the behaviour of short and long cracks under cyclic loading by using low cycle fatigue tests (LCF).

\section{Materials}

The chemical composition of the studied T91 satisfies the standard. Expressed in wt\%, it contains $0.1 \mathrm{C}, \mathbf{8 . 9 9}$ Cr, 0.89 Mo, 0.06 Nb, 0.21 V, 0.38 Mn, 0.22 Si, 0.11 $\mathrm{Ni}$,

0. $0146 \mathrm{Al}, 0.06 \mathrm{Cu}, 0.0034 \mathrm{Ti}, 0.01 \mathrm{~W}, 0.021 \mathrm{P}$, $0.0004 \mathrm{~S}$, Fe bal.

The material 91 was heat treated at $1100^{\circ} \mathrm{C}$ for 15 minutes followed by water cooling and a subsequent tempering for 45 minutes at $770^{\circ} \mathrm{C}$ and then air cooling.

The microstructure is a fully tempered martensite (Figure 1) with an average hardness value of $220 \mathrm{HV}$.

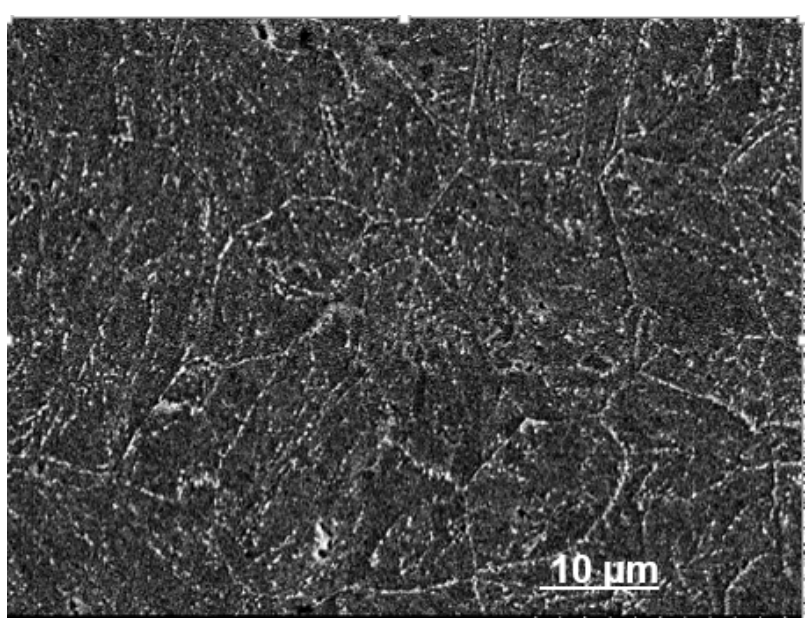


Fig. 1. SEM micrograph of the material before fatigue testing

The chemical composition of the liquid metallic alloy is $45 \mathrm{wt} \%$ lead and $55 \mathrm{wt} \%$ bismuth (LBE).

\section{Low cycle fatigue details}

A tank and samples specifically designed to perform LCF tests in LBE were machined. The specimens were smooth and cylindrical with a gauge length of $10 \mathrm{~mm}$ and a gage diameter of $6 \mathrm{~mm}$. In order to avoid effects due to the roughness of the surface and to residual stresses developed during the machining, the sample surface was carefully electro polished. The fatigue tests were carried out using a servo-hydraulic Schenk machine with a load capacity of $250 \mathrm{kN}$ under total axial strain control $\Delta \varepsilon_{\mathrm{t}}$ ranging from $0.40 \%$ to $1.2 \%$. A fully push pull mode $\left(\mathrm{R}_{\varepsilon}=-1\right)$, a triangular waveform and a constant strain rate of $4.10^{-3} \mathrm{~s}^{-1}$ were used. All the tests were carried out at $350^{\circ} \mathrm{C}$ in air and in LBE.

The specimen was immersed into a small reservoir containing the LBE (Figure 2) which could not accept the extensometer to be attached onto the specimen. Therefore, the strain control was performed by using a strain gage extensometer fixed outside of the specimen.

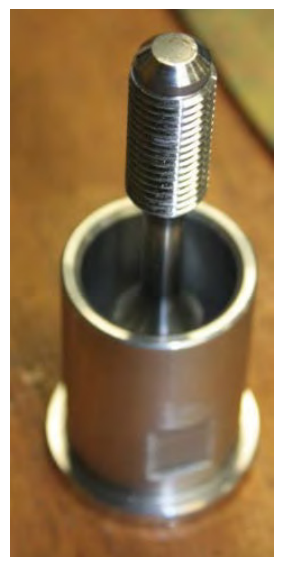

Fig. 2. Picture showing the specimen in the LBE reservoir

The fatigue life $\mathrm{N}_{f}$, is defined as the number of cycles needed for a $25 \%$ drop in the tensile stress taking as a reference the (pseudo) stabilized hysteresis loop

\section{Results}

\subsection{Stress response to strain cycling}

Except for the test performed at $\Delta \varepsilon_{\mathrm{t}}=0.4 \%$, the material cycled at $350^{\circ} \mathrm{C}$ presents a strong tendency to softening at the beginning of cycling and then at a moderate rate (see Figure 3). Then the fall of the stress is more moderate. Finally a marked decrease of the stress amplitude occurs that is related to the propagation of a macroscopic crack into the bulk just before the final failure.

Except for the final decrease in the stress amplitude which is affected by the liquid metal, the same overall behaviour is observed when cycling in the LBE environment. Note that the amount and duration of the initial softening clearly depends on the applied strain range only.

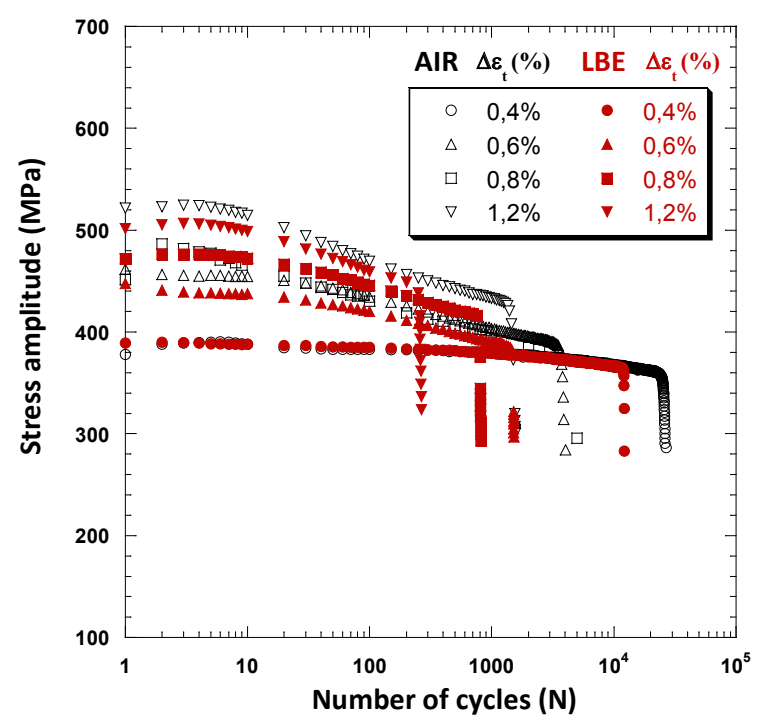

Fig. 3. Evolution of the stress amplitude with the number of cycles of T91 steel fatigued in air and $\mathrm{LBE}$ at $350^{\circ} \mathrm{C}$

\subsection{Effect of LBE on fatigue crack initiation resistance}

The evolution of the total strain range as a function of the number of cycles to failure is plotted Fig. 4.

The main effect of $\mathrm{LBE}$ is to reduce the fatigue resistance in comparison with tests performed in air. Such an influence of a liquid metal on fatigue resistance has been reported for the Manet II martensitic (Fe-10Cr$0.8 \mathrm{Mn}-0.2 \mathrm{~V}-0.1 \mathrm{C}$ ) in $\mathrm{LBE}$ at $260^{\circ} \mathrm{C}$ [5] and in $\mathrm{T} 91$ at $300^{\circ} \mathrm{C}[6]$ and $350^{\circ} \mathrm{C}$ [7].

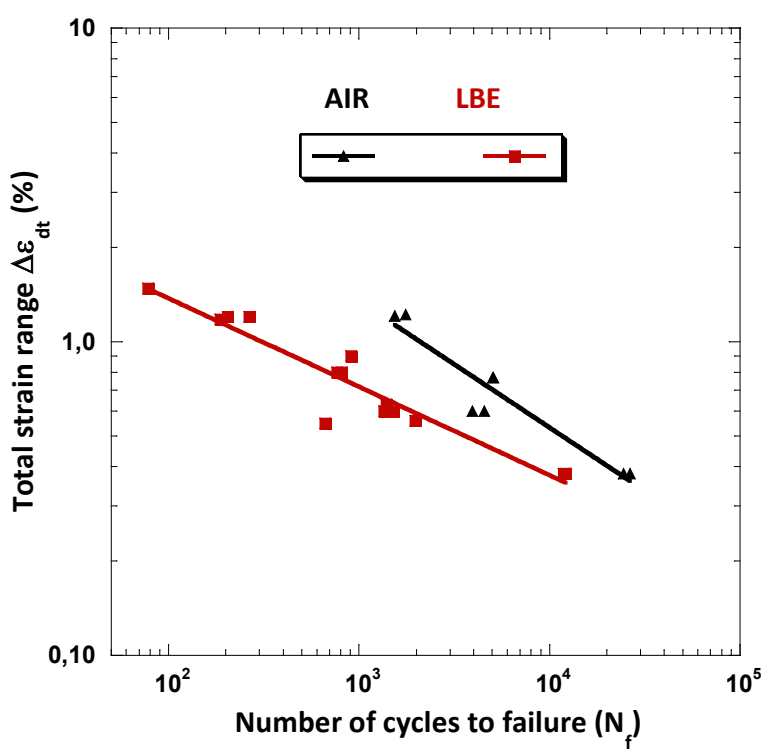


Fig. 4. Evolution of the total strain range with the number of cycles to failure of T91 steel fatigued in air and LBE at $350^{\circ} \mathrm{C}$

\subsection{Effect of LBE on fatigue crack propagation resistance}

Normally, the study of fatigue crack propagation is performed by using pre-cracked specimens in order to connect the fatigue crack velocity $\mathrm{da} / \mathrm{dN}$ to the cyclic stress intensity factor $\Delta \mathrm{K}$. This could not have been performed. However, the final part (the last 10 percents of the fatigue life) of the curves stress amplitude-number of cycles was analysed for that.

For each test, $\Delta \mathrm{N}_{5 \%-25 \%}=\mathrm{N}_{25 \%}-\mathrm{N}_{5 \%}$ was calculated where $\Delta \mathrm{N}_{25 \%}$ and $\Delta \mathrm{N}_{5 \%}$ are the number of cycles correspond to a $25 \%$ drop in the tensile stress and to a $5 \%$ drop in the tensile stress respectively.

The result is reported in figure 5 .

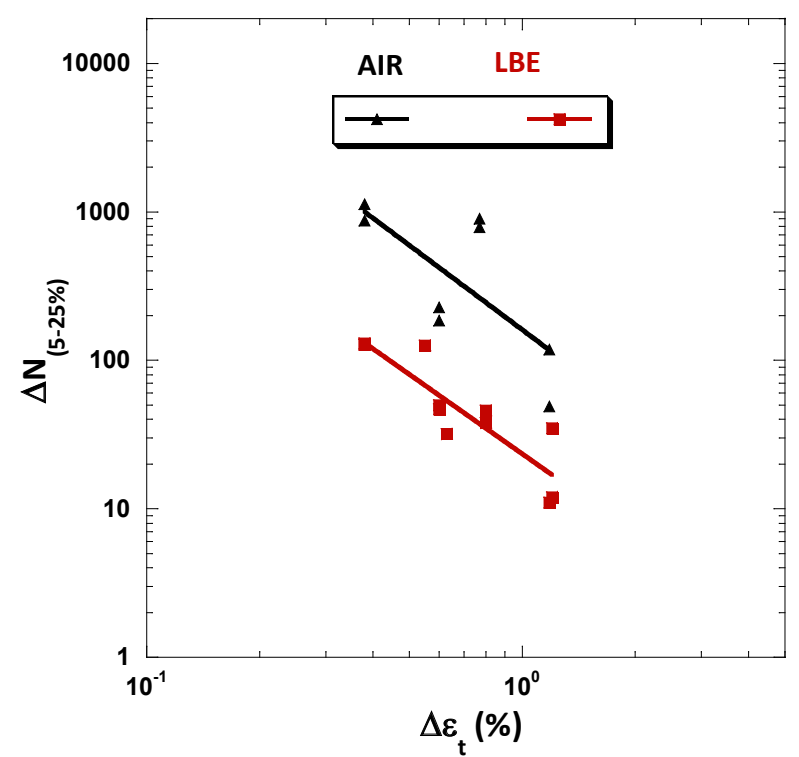

Fig. 5. Evolution of the number of cycles for propagation of the long crack versus the total strain range of T91 steel fatigued in air and $\mathrm{LBE}$ at $350^{\circ} \mathrm{C}$

\subsection{Short crack analysis}

Fatigue specimen were cut transversally in order to appreciate the number and the depth of the short cracks. After cutting, the specimen were polished to have a mirror surface and then were etched with the Villela etchant. After fatigue in air, it was possible to observe on the transverse cross sections a lot of short cracks of different lengths (Figure 6).

After fatigue in LBE, the number of short cracks was considerably reduced so that it can be considered that only the main crack was visible. (Figure 7).

The strain range had a noticeable effect on the density of short cracks in air, i.e. the density increased with the strain range, but not for the tests performed in LBE.

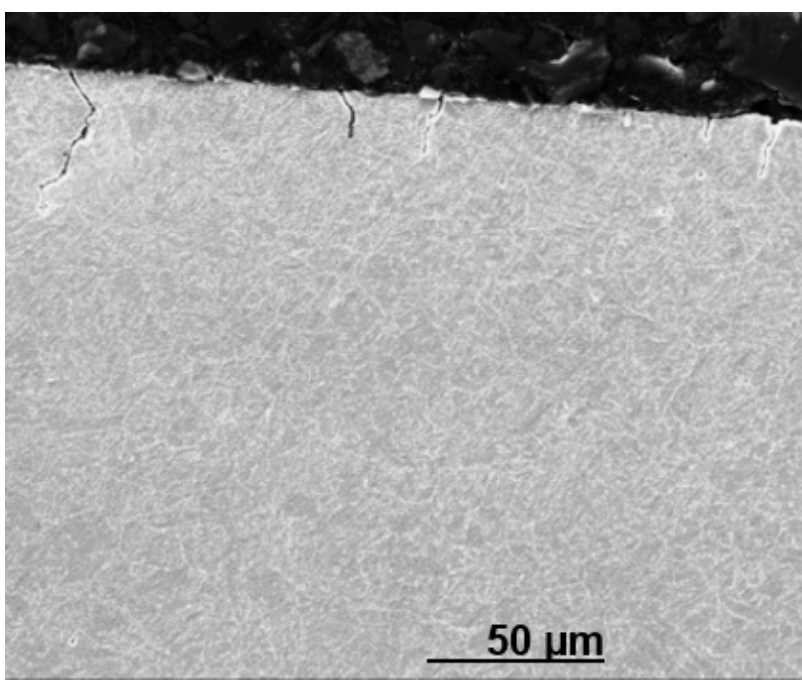

Fig. 6. Observation of short cracks in T91 steel fatigued in air at $350^{\circ} \mathrm{C}$ and $\Delta \varepsilon_{\mathrm{t}}=1.2 \%$

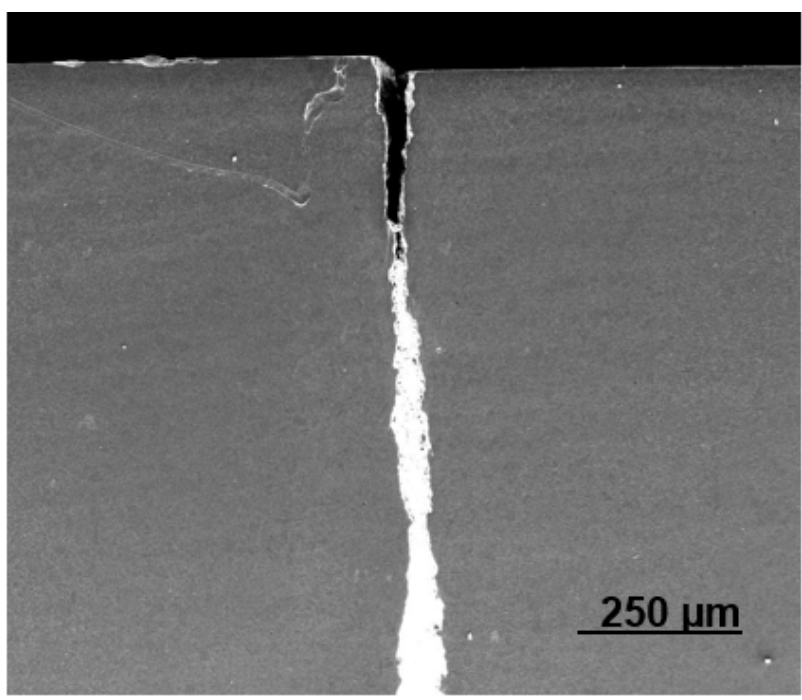

Fig. 7. Observation of short cracks in $\mathrm{T} 91$ steel fatigued in LBE at $350^{\circ} \mathrm{C}$ and $\Delta \varepsilon_{\mathrm{t}}=0.6 \%$

\subsection{Long crack analysis}

The long crack morphology was first observed directly on the gage length of the specimen.

After fatigue in air, the main crack was accompanied by a rough zone. The rough aspect tended to vanish gradually the observation left the crack tip. However, even at $1 \mathrm{~mm}$ from the crack tip, the plastic deformation was still visible.

After fatigue in LBE, the crack path appeared more serrated without any roughness on the lips.

The most striking difference between cycling in air and in LBE was the fracture surface morphology. In air, in agreement with the short crack distribution, the fracture surface contained multiple crack initiation sites from which several cracks propagate by fatigue in the bulk and a final fracture due to monotonic loading. Fatigue striations could be observed by SEM. The fracture surfaces of specimen cycled in LBE are totally different. First, the fracture surface was very flat and contained a single initiation site from which the crack 
propagated by cyclic loading. The final fracture occurred by pure tensile loading. On the fracture surface related to cyclic loading, it was possible to see at very low magnification, and even with the naked eye, curved striations (Figure 8). For a given strain range, the distance between two striations increased as long as the crack advanced in the bulk.

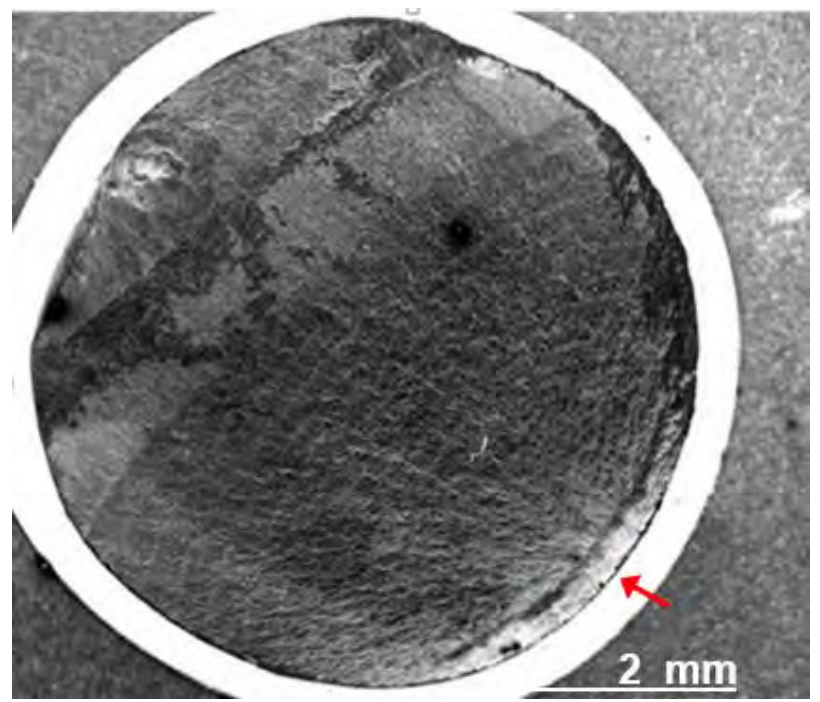

Fig. 8. Macroview of the fracture surface of T91 steel fatigued in $\mathrm{LBE}$ at $350^{\circ} \mathrm{C}$ and $\Delta \varepsilon_{\mathrm{t}}=1.2 \%$ (the red arrow indicates crack initiation site)

At higher magnification, SEM observations pointed out transgranular brittle fracture (Figure 9).

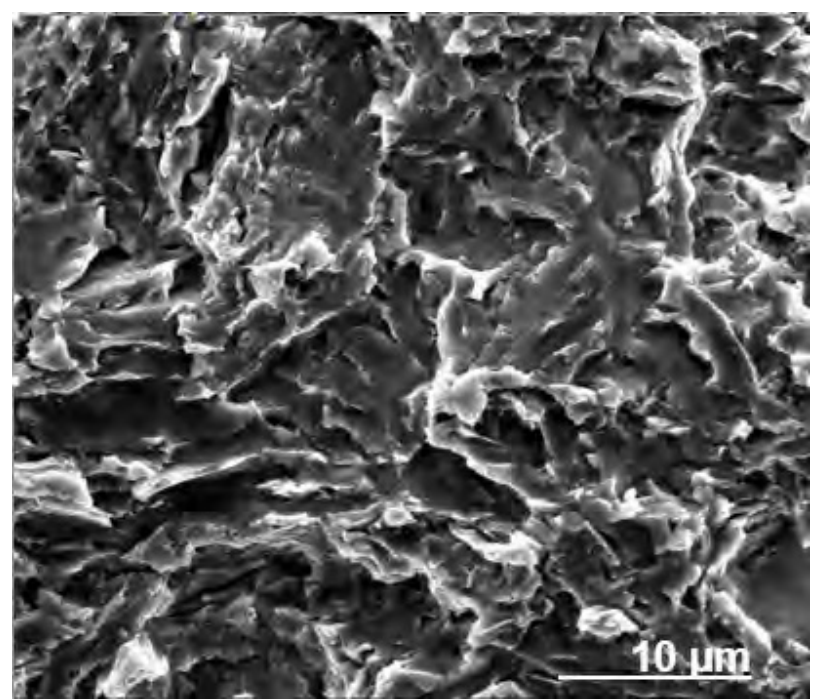

Fig. 9. SEM observation of the fracture surface between two striations of $\mathrm{T} 91$ steel fatigued in $\mathrm{LBE}$ at $350^{\circ} \mathrm{C}$ and $\Delta \varepsilon_{\mathrm{t}}=1.2 \%$ showing brittle fracture

SEM-EBSD analysis were performed on specimen fatigued in air and in $\mathrm{LBE}$ at $\Delta \varepsilon_{\mathrm{t}}=1.2 \%$. When the long crack was supposed to propagate in the bulk, then the test was stopped, the specimen removed and cut along the loading direction. Specific preparation was performed to obtain high quality EBSD patterns and further processing. EBSD patterns were acquired far away from the crack to have a reference state, on the crack lips very close to the external surface, at $2.5 \mathrm{~mm}$ from the external surface and very near the crack tip.

For the specimen fatigued in air, the inverse pole figures (IPF) revealed that the crack lips were decorated by a continuous raw of misoriented fine grains in the very first micrometers of the material adjacent to the fracture surface (Figure 10). The grains were highly misoriented and had a grain size ranging from $0.25 \mu \mathrm{m}$ to $0.5 \mu \mathrm{m}$.

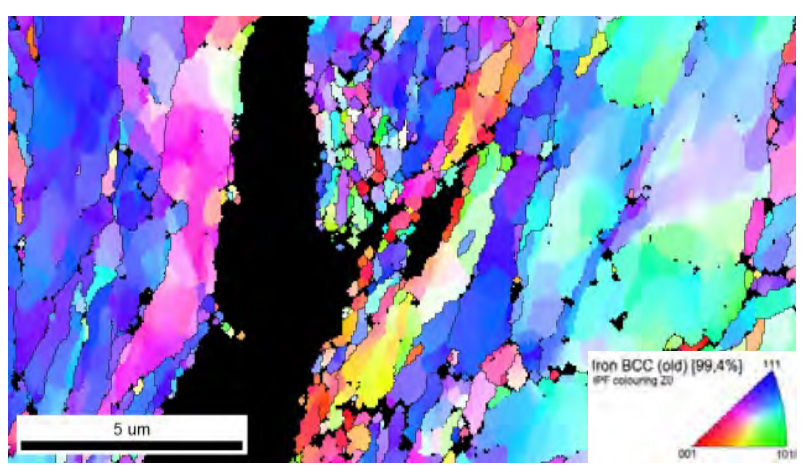

Fig. 10: IPF acquired near the crack tip in T91 fatigued in air at $350^{\circ} \mathrm{C}$ and $\Delta \varepsilon_{\mathrm{t}}=1.2 \%$

This was not observed for the specimen failed in LBE except at some spots where small groups of misoriented fine grains similar to those observed in the specimen fatigued in air could be observed (Figure 11).

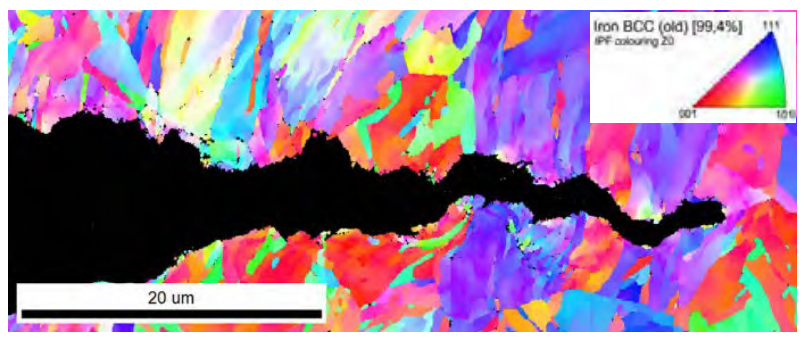

Fig. 11: IPF acquired near the crack tip in T91 fatigued in LBE at $350^{\circ} \mathrm{C}$ and $\Delta \varepsilon_{\mathrm{t}}=1.2 \%$

\section{Discussion}

The present investigation performed on T91 shows a conventional response typical of martensitic steel i.e. a cyclic softening. This is in accordance with the microstructure resulting from the heat treatment which produced and arranged a high density of dislocations. Annihilation can explain the softening and since it is a bulk effect, there is no reason why the presence of LBE should modifies the response. Therefore, in air as well in LBE, slip bands can emerge at the surface and intrusionextrusion pairs can form. Intrusions are preferential sites for short crack initiation and their developments are sensitive to the presence of the environment.

In air, the very first short cracks with a dimension of a grain size are hindered by the presence of grain boundaries (including a misorientation effect between the grains) which can be overcome after a given number of cycles. The crack extension proceeds by 
crystallographic growth and may again be delayed by other grain boundaries as its length reached three or four grain sizes. Longer microcracks (up to ten grain sizes typically) can eventually form by the coalescence of the shorter cracks and finally, only a very few of them propagated into the bulk perpendicularly to the stress axis.

In LBE, the absence of short cracks is a clear indication that the liquid metal provided a driving force to the very first short cracks to overcome the structural barriers.

The presence of fatigue striation in specimen fatigued in air is a clear indication that the crack propagated in a ductile manner. The very small distance between striations suggests that the crack extension is slow and involves plastic deformation during tensile and compressive phase of the loading signal. The striations may be the result of successive blunting and resharping due to plastic deformation at the crack tip. In LBE, the large distance between striations indicates that the crack advanced rapidly. And this is in good agreement with the observations of brittle transgranular fracture. The modification of fracture mode between fatigue in air and fatigue in LBE is a simple appearance of LME. There are several explanations and models for LME. In our situation, the brittle fracture theory proposed by Stoloff and Johnson[8] \& Westwood and Kamdar [9] and based on the weakening of inter-atomic bonds by the liquid metal atoms at the crack sounds well. LME occurrence requires an actual wetting between atoms of the liquid metal and the steel. This can be not encountered if the crack tip is not wetted due to capillarity. However, in our case, EDX analysis of the crack tip after fatigue in LBE clearly showed that the liquid metal reached the very crack tip. Another reason for the non wetting is the presence of an oxide film. In the present experiments, LBE was oxygen saturated which means that even fresh surface formed in the LBE, dissolved oxygen can react with the fresh steel to form an oxide film. However, the stability of the oxide film is disturbed due to very localized plasticity. And this allows atoms to adsorb the steel and to promote a liquid metal assisted crack propagation.

Finally, the EBSD analysis revealed a very strong and localized activity of cyclic plasticity at tip of a crack propagating in air in which recrystallization operated and gave rise to new fine grains. The absence of such fine grains in large portion of the crack lip in specimen fatigued in LBE is well in agreement with brittle fracture. The presence of fine grains at some spots of the lips may be explained by the temporary arrest of the brittle crack due to temporary non-wetting of the surface by the atoms of the liquid metal.

\section{Conclusion}

The low cycle fatigue behaviour of the T91 martensitic steel has been investigated at $350^{\circ} \mathrm{C}$ in air and in LBE. $\mathrm{LBE}$ accelerates the formation of the long crack by promoting the growth of the first short cracks. In LBE, the long crack advanced quickly by repeated and discontinuous cleavage.

\section{Acknowledgements}

The work was partly funded by the European Atomic Energy Community's (Euratom) Seventh Framework Programme FP7/2007-2013 under Grant agreement no. 604862 (MatISSE project)

\section{References}

1. Y. Dai, J. Henry, Z. Tong, X. Averty, J. Malaplate, B. Long, J. Nuc. Mat., 415, 306, (2011)

2. J. Blach, L. Falat, P. Ševc, Eng. Failure Analysis, 16, 1397 (2009)

3. M. El May, N. Saintier, O. Devos, A. Rozinoer, Procedia Engineering, 133, 528 (2015)

4. I. Serre, J.-B. Vogt, J. Nucl. Mater., 376, 330, (2008)

5. D. Kalkhof, M. Grosse, J Nucl Mater, 318, 143, (2003)

6. A. Verleene, J.-B. Vogt, I. Serre, A. Legris, Int. J. Fatigue, 28, 843 (2006)

7. X. Gong, P. Marmy, B. Verlinden, M. Wevers, M. Seefeldt, Corros. Sci. 94377 (2014)

8. N. S. Stoloff, T. L. Johnston, Acta. Met., 11, 251 (1963)

9. A.R.C. Westwood, M.H. Kamdar, Philos Mag 8, 787,(1963) 